Article

\title{
How does the Ecological Well-Being of Urban and Rural Residents Change with Rural-Urban Land Conversion? The Case of Hubei, China
}

\author{
Min Song ${ }^{1,2, *(1)}$, Lynn Huntsinger ${ }^{2}$ and Manman Han $^{3}$ \\ 1 School of Business Administration, Zhongnan University of Ecomomics and Law, Wuhan 430073, China \\ 2 Department of Environmental Science, Policy and Management, University of California at Berkeley, \\ Berkeley, CA 94720-3110, USA; huntsinger@berkeley.edu \\ 3 Department of Land Management, Zhejiang University, Hangzhou 310058, China; hanman1016@163.com \\ * Correspondence: songmin0211@hotmail.com; Tel.: +86-189-862-43230
}

Received: 4 January 2018; Accepted: 14 February 2018; Published: 15 February 2018

\begin{abstract}
Human well-being can be affected by the loss of ecosystem services from conversion of agricultural lands. Uncovering negative ecological consequences of rural-urban conversion is important for regulating rural-urban land conversion. This paper evaluates the impacts of rural-urban land conversion on the ecological well-being of different interest groups in China and makes policy recommendations for mitigating them. This research empirically quantifies and compares changes in the ecological well-being of rural and urban residents due to rural-urban land conversion and examines how transformation factors affect such changes in Hubei, China using the Fuzzy Synthetic Evaluation Model. Results show that compared with urban residents, rural resident ecological well-being level declines more obviously with rural-urban land conversion. Two socio-demographic characteristics, age and education level, as well as zoning characteristics, influence both rural and urban resident well-being changes. It is argued that there is a need for quantitative measurement of agricultural ecosystem services changes and that the construction of ecological compensation policies in areas undergoing rural-urban land conversion is essential for regulating rural-urban land conversion and for maintaining resident ecological well-being.
\end{abstract}

Keywords: ecological well-being changes; rural-urban land conversion; transformation factors; urban residents; rural residents; China

\section{Introduction}

Humans are dependent upon the services provided by nature and unless we effectively account for the range of values from ecosystems in our efforts to protect the environment, we cannot sustain human well-being [1,2]. Land use and land cover change (LUCC) is a driver of global change that directly influent the status and integrity of ecosystems and in last term its capacity to supply ecosystem services [3]. While human well-being, as an endpoint and central yardstick for sustainability, is widely recognized as an important issue but is difficult to be studied empirically [4-6]. One of the outcomes of urbanization in China, "rural-urban land conversion" is the change from agricultural land in rural areas to developed urban land which is a kind of LUCC [7,8]. Rural-urban land conversion provides land element for urban sprawl, industrial development and economic growth. But it also presents a challenge to the ecological system because many ecosystem services provided by agricultural land are lost in the process of conversion, which can be described as the negative external ecological effects of rural-urban land conversion [9-13]. Fortunately, such losses in human well-being have received increasing attention in economic analysis and public policy making, based on the ecosystem services functions as well as human well-being indicators made in the Millennium Ecosystem Assessment 
(MA) [14-17]. Currently, some empirical studies aimed to uncover the relationship between land use change or ecosystem services and human well-being have been reported in many countries, including the U.S. [18], Brazil [19], South Africa [20], China [6], Spanish [3] and the U.K. [21]. However, the issue of how to quantify the changes in ecological well-being of rural and urban residents due to rural-urban land conversion and how conversion factors affect such changes has not been adequately studied [22-24]. In view of this, this paper constructs an ecological well-being index for residents, quantifies the changes in ecological well-being of residents caused by rural-urban land conversion and examines the impact of transformation factors (socio-demographic characteristics and zoning characteristics) on these changes for rural and urban residents.

The agricultural social-ecological system includes agricultural land, the natural environment and human interventions. It is commonly characterized as semi-natural and semi-artificial [25-27]. The agroecosystem provides not only agricultural products including grain, fiber, vegetable, wood and fishery products but also multiple ecological services such as air purification, climate regulation, soil stability and eco-landscapes $[14,28,29]$. With the acceleration of land-based urbanization in China since the 1980s, the population has been migrating to urban areas triggering unprecedented, fierce land competition and tremendous land use changes. The character of rural-urban land conversion in China in the last 30 years has been described as 'accelerating urban expansion, establishing the eastern part of China as the center of gravity and extending out to the Midwest of China' [16]. Rural-urban land conversion transfers the semi-natural landscapes to a landscape of buildings and roads. The biological community, soils, water flow and surface structure of agricultural lands is destroyed in this process which means that the land's original ecosystem degrades [30-32]. The capability of agricultural land to providing various ecological services is diminishing and declining accordingly [33]. Therefore, rural-urban land conversion which is a common social-economic phenomenon in developing countries has significant negative externalities from the ecological point of view $[13,31,34,35]$. Such land use transitions had negative effects on local ecological systems and human well-being may decline when these negative externalities are ignored and incorrectly treated [3,36,37]. In 2005, the MA presented a conceptual framework which revealed the interactions between ecosystem services, human well-being and the driving forces of change and it pointed out that ecosystem services (including provision services, regulating services, cultural services and supporting services) are closely related to human well-being. Human well-being was explained as the basic material for a good life, health, good social relations, security and freedom of choice and action [38,39]. In view of these, the human well-being discussed in this paper is limited to those factors closely associated with ecosystem services and termed "human ecological well-being".

The existing research usually focuses on the evaluation of a certain kind of ecological service from the agricultural ecosystem, such as supply services that underpin basic livelihood capacity [40], coordinating services that can prevent extreme weather, conserve water and purify the air [31,41], support services that provide habitat for plants and animals and maintain the potential for sustainable use of agricultural land resources in the future [42,43], as well as cultural services that include educational opportunities, inspiration, entertainment and local identity [44-46]. Scholars in China have paid close attention to the changes in the overall welfare of some stakeholders in the process of rural-urban land conversion [11,47,48], especially the overall welfare of farmers [49-51]. Most of these papers used the theories and methods of welfare economics to calculate the economic or material welfare changes caused by rural-urban land conversion, while neglecting the impact of ecosystem change on human well-being from the externalities of land use change [40]. In recent years, some scholars have begun to link human ecological well-being loss with ecosystem change from the perspective of the relationship between ecosystem services and human well-being, based on the framework for ecosystem services as well as human well-being constituents from the MA [15,17,52]. Such research calls for the investigation of resident ecological well-being changes in the process of rural-urban land conversion. Of quantitative measurement methods, the most commonly used methods are stated-preference methods including the Contingent Valuation Method (CVM), Choice 
Experiment Method (CE), etc. [44-46]. However, these methods have some inherent defects, to be more specific, CVM can only estimate a well-being change caused by one certain state of environmental change and the accuracy of its result is affected by more than ten kinds of inherent latent deviations such as hypothetical deviation, partial-global deviation, strategic deviation, etc. [53,54]. Although CE is able to calculate the economic value of different attributes of resources, its estimation accuracy depends on the authenticity and reliability of the survey data and is influenced by embedding bias, hypothetical deviation, etc. [55]. Therefore, the systematic research on the relationship between agroecosystem services and human well-being needs to be further advanced in terms of content and method.

Moreover, for the sake of protecting limited agricultural land, China implemented the world's most stringent Land Use Control System starting in the 1980s, upgrading to Land Use Spatial Control in recent ten years. It can be seen as a conversion from reserving the quantity of agricultural land to regulating agricultural land protection spatially $[13,56,57]$. Specifically, Land Use Spatial Control in China divides the entire land space into four major function oriented zones including the Optimizing Development Zone, Key Development Zone, Restricted Development Zone as well as the Forbidden Development Zone according to resource and environment carrying capacity, existing development density and development potential, natural environmental constituents, the level of socio-economic development, ecosystem characteristics and the spatial differentiation of human activities in different areas. This raises some questions, notably, when rural-urban land conversion occurs in the different zones, are there different changes in the ecological well-being of residents? Investigation of this question can provide a basis for the implementation of spatially heterogeneous ecological compensation mechanisms for agricultural land protection.

The goal of this paper, therefore, is to examine the specific human well-being constituents that closely relate to the ecological services from agricultural lands and which foster "human ecological well-being". We construct an evaluation index for resident ecological well-being, quantify the changes in ecological well-being of residents due to rural-urban land conversion and analyze the effect of individual and zoning transformation factors. We examine impacts on both rural and urban residents: we hypothesize that both are affected by the agroecosystem because of spillover effects but that they are affected differently owing to their different relationship with and distance from agricultural lands. The research findings from this study provide a foundation for evaluating impacts of conversion on the ecological well-being of different interest groups, for regulating rural-urban land conversion by zoning and for establishing an efficient ecological compensation mechanism for rural-urban land conversion.

\section{Constituents of Resident Ecological Well-Being}

The Millennium Ecosystem Assessment (MA) was called for by United Nations Secretary-General Kofi Annan in 2000 and had lasted for 4 years since it was initiated in 2001. The objective of the MA was to assess the consequences of ecosystem change for human well-being and to establish the scientific basis for actions needed to enhance the conservation and sustainable use of ecosystems and their contributions to human well-being. Two of the four core questions of MA are "Who caused the ecosystem and their services change and how these changes affected human well-being?" In 2005, the MA presented a conceptual framework which revealed the interactions between ecosystem services and human well-being and it pointed out that ecosystem services (including provision services, regulating services, cultural services and supporting services) are closely related to human well-being (including the basic material needs for a good life, health, good social relations, security and freedom of choice and action) [38]. On this basis, series indices are selected in this paper to set up the evaluation index system for resident ecological well-being based on the classification for human well-being constituents of MA, combined with the characteristics of agroecosystem and the existing literature about human well-being (Figure 1 and Table 1). In view of the different ecological impacts on rural and urban residents from rural-urban land conversion, the specific indices of ecological well-being for the two groups are slightly different (Table 1). 


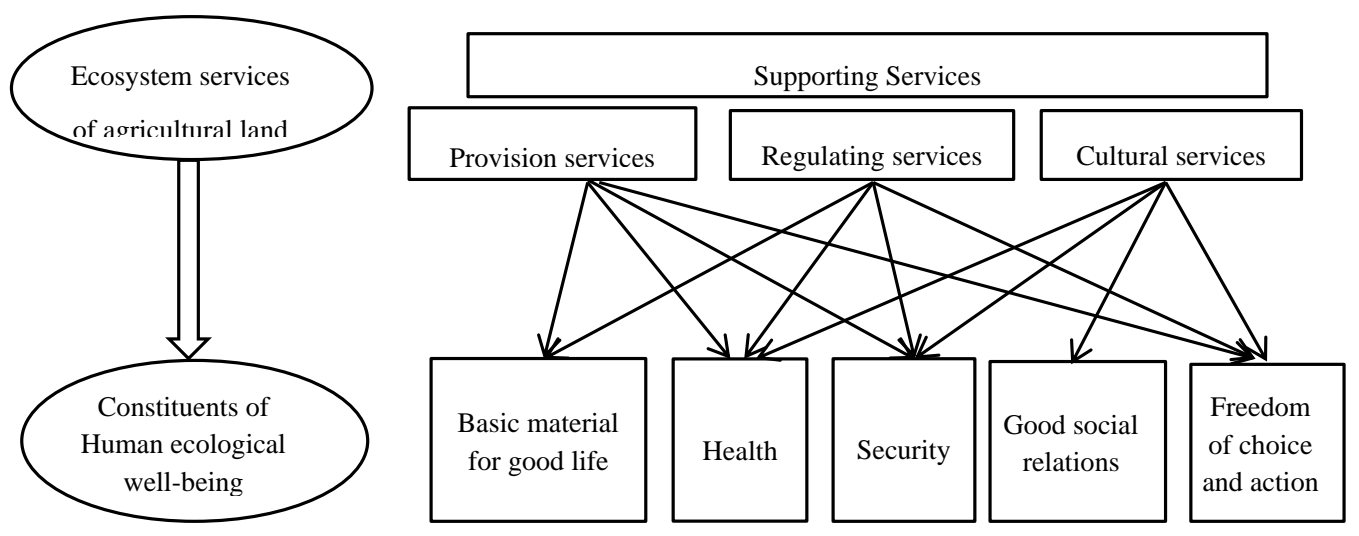

Figure 1. Relationship between agro ecosystem services and human ecological well-being.

Table 1. Index system of resident ecological well-being.

\begin{tabular}{|c|c|c|c|}
\hline \multirow{2}{*}{$\begin{array}{l}\text { Constituents of } \\
\text { Ecological Well-Being }\end{array}$} & \multirow{2}{*}{ Criterion } & \multicolumn{2}{|c|}{ Indices } \\
\hline & & Rural residents & Urban residents \\
\hline \multirow{2}{*}{ Security $\mathrm{X}_{1}$} & Access to clean and secure living spaces & \multicolumn{2}{|l|}{ Waste recycling capability $X_{11}$} \\
\hline & $\begin{array}{l}\text { Reduction of environmental attack and } \\
\text { threats }\end{array}$ & \multicolumn{2}{|c|}{$\begin{array}{l}\text { Frequency of agroecosystem-related meteorological disasters } \\
\text { (such as drought, floods, soil erosion and desertification) } X_{12}\end{array}$} \\
\hline $\begin{array}{l}\text { Basic material for a } \\
\text { good life } \mathrm{X}_{2}\end{array}$ & $\begin{array}{l}\text { Access to resources for income and } \\
\text { livelihood }\end{array}$ & \multicolumn{2}{|l|}{$\begin{array}{l}\text { Obtain daily staple food } X_{21} \\
\text { Obtain daily vegetables } X_{22} \\
\text { Obtain daily meat } X_{23}\end{array}$} \\
\hline \multirow{4}{*}{ Health $X_{3}$} & Access to clean air & \multicolumn{2}{|l|}{ Satisfaction with air quality $X_{31}$} \\
\hline & Access to adequate and clean water & \multicolumn{2}{|l|}{ Satisfaction with water quality $\mathrm{X}_{32}$} \\
\hline & Obtain adequate nutrition & \multicolumn{2}{|c|}{ Safety of food, vegetables and meat consumption $X_{33}$} \\
\hline & Avoidance of preventable diseases & \multicolumn{2}{|l|}{ Pollution-related diseases $X_{34}$} \\
\hline \multirow[t]{2}{*}{$\begin{array}{l}\text { Good social relations } \\
\mathrm{X}_{4}\end{array}$} & $\begin{array}{l}\text { Opportunities to express cultural and } \\
\text { spiritual values associated with the } \\
\text { ecosystem }\end{array}$ & \multicolumn{2}{|l|}{$\begin{array}{l}\text { Rural life nostalgia } \mathrm{X}_{41} \\
\text { Children's rural experiences } \mathrm{X}_{42}\end{array}$} \\
\hline & $\begin{array}{l}\text { Opportunities to experience the aesthetic } \\
\text { and recreational values associated with } \\
\text { the ecosystem }\end{array}$ & & $\begin{array}{l}\text { Frequency of ecotourism } X_{43} \\
\text { Satisfaction with the natural } \\
\text { landscape } X_{44}\end{array}$ \\
\hline $\begin{array}{l}\text { Freedom of choice and } \\
\text { action } X_{5}\end{array}$ & $\begin{array}{l}\text { Achieving the status of valuable survival } \\
\text { state }\end{array}$ & \multicolumn{2}{|l|}{ Livelihood choices $X_{51}$} \\
\hline
\end{tabular}

\subsection{Security}

The MA recognizes that the security refer to safety of person and possessions, secure access to necessary resources and security from natural and human-made disasters [38]. Rural-urban land conversion weakens the land's capacity for water conservation, weather moderation and waste recycling [31,40]. The recycling of surface runoff and flood regulation are significantly affected [31]. This paper selects the indices of waste recycling and the frequency of meteorological disasters (such as drought, floods, soil erosion and desertification etc.), which are related to the agricultural ecosystem, to characterize resident well-being level for the security constituent. What needs to be explained is that the index of waste recycling capability is only for rural resident survey and analysis, because waste needs ecosystems to degrade in many rural areas where still short of complete waste disposal system.

\subsection{Basic Materials for a Good Life}

Basic material for a good life refers to the ability to have a secure and adequate livelihood, including income and assets, enough food and water at all times, shelter, ability to have energy to keep warm and cool and access to goods [38]. Agroecosystem synthesize organic compounds by solar energy and artificial auxiliary energy, providing the fundamental materials for human life [58]. Rural-urban land conversion changes the basic material conditions of rural residents as the direct users 
of agricultural land. Therefore, the existing compensation institutions for agricultural land acquisition should not only take economic compensation into account but also compensation for degradation of access to ecosystem resources [40]. In the assessment's conceptual framework of interactions between ecosystem services and human well-being constructed by MA, one of the services-the provisioning service-refers to the products obtained from the ecosystem. Changes in provisioning services such as food, water and fuelwood have very strong influences on the adequacy of material for a good life. And it is also stated that the access to these materials is heavily mediated by socioeconomic circumstances [38]. This research focuses on agroecosystem which produce food mainly. Besides, in many underdeveloped rural areas in China, farming is still the main way for farmers to get food to meet the basic need of life. Therefore, this paper uses changes in the way that rural residents obtain daily ingredients (staple food, vegetables and meat) to represent the change in basic materials for a good life. It should be noted that the relationship between an urban resident's basic materials for a good life and the agroecosystem is not significant, because on the one hand, they have no direct connection with the agricultural land (they do not farm), on the other hand, as a relatively wealthy group, local changes in ecosystems may not cause a significant change in their access to necessary material goods [38]. Accordingly, this paper considers that the basic materials for an urban resident's good life remain unchanged in rural-urban land conversion. So the indices of obtained daily staple food, obtained daily vegetables and obtained daily meat, which are employed to characterize the constituents of basic materials for a good life, are only used for the rural resident survey and analysis.

\subsection{Health}

The MA states that the constituent of health is the ability of an individual to feel well and be strong, or in other words to be adequately nourished and free from disease, to have access to adequate and clean drinking water and clean air and to have the ability to have energy to keep warm and cool [38]. Rural-urban conversion destroys the nutrient recycling capacity of agroecosystem [59-62]. Therefore, this paper investigates the satisfaction of rural and urban residents with their daily consumption of staple food, vegetables and meat to measure the change in their capability of obtaining enough nutrition. Existing studies also suggest that agroecosystem have the function of blocking and absorbing a certain amount of particulate waste [63], preventing the deterioration of river water [64] and controlling the spread of epidemic diseases [58]. In view of these, in this paper, the capability of avoiding preventable diseases is measured by the indices of number of ecological pollution-related diseases. Access to adequate and clean water as well as clean air is measured by the indices of resident satisfaction with water quality and air quality separately.

\subsection{Good Social Relations}

Good social relations can be explained as the presence of social cohesion, mutual respect and the ability to help others and provide for children [38]. The capability of providing aesthetic values and interactions between human and the ecological environment offered by agricultural lands have been recognized as vital service functions $[17,65]$. Rural-urban land conversion typically triggers aesthetic damage [66]. For urban residents, the decline of agricultural land reduces their opportunities for rural tourism, agritainment, etc. In this paper, the constituents of good social relations for urban residents are measured by indices of frequency of ecotourism and satisfaction with the natural landscape. Agroecosystem fosters specific agricultural cultures which include agricultural production activities and rural lifestyles [67] and also the link between humans and nature as well as humans and society [44]. In China, farmers are strongly attached to their agricultural land. A deep and irreversible ruin of the cultural and spiritual heritage of rural areas takes place when rural-urban land conversion proceeds [68].Therefore, the constituent of good social relations for rural residents is characterized by indices of rural life nostalgia and children's rural experiences. 


\subsection{Freedom of Choice and Action}

Freedom of choice and action refers to the ability of individuals to control what happens to them and to be able to achieve what they value doing or being [38]. The basic livelihood of rural populations depends mainly on the services provided by agroecosystem [40]. Agricultural populations who live in poor areas are influenced by land use change more directly and profoundly [69].

Before rural-urban land conversion, rural residents have the freedom to make choices between farming and working in urban areas. However, after the rural-urban land conversion, their livelihood choices are more limited because they have no other choice but to work in urban areas. Their low level of education and inadequate non-agricultural labor skills exacerbate this limitation. While for urban residents, rural residents entering urban areas to work compete for the available jobs. Therefore, this paper uses livelihood choices as an index to measure changes in resident freedom of choice and action.

\section{Materials and Methods}

\subsection{Study Area}

Wuhan City and Shiyan City in Hubei Province were selected as the study area (Figure 2). Wuhan City which is located in a Key Development Zone according to the Main Function Oriented Division (MFOD) is a megalopolis in middle of China. Wuhan City, with an urbanization rate of $71.7 \%$ at the end of 2016, significantly higher than any other city in Hubei province, is developing at soaring speed in recent years. It is in the phase of accelerated urbanization which accompanies rapid urban expansion. Wuhan City has 13 districts, including 7 central districts and 6 suburban districts. The latter is composed of Jiaxia district, Caidian district, Huangpi district and so on and the area with the highest rate of rural-urban land conversion in the last few years. However, Shiyan City, located in the northwest border of Hubei Province, is in a Restricted Development Zone. It is not only a poor region of the Qin-ba mountain area but also the Core Water Source Area of the Middle Route of the South-to-North Water Diversion Project. This city, which has adopted a "focus on ecology externally and focus on humanities internally" as its development strategy is now facing the dilemma of balancing ecological protection and economic development.

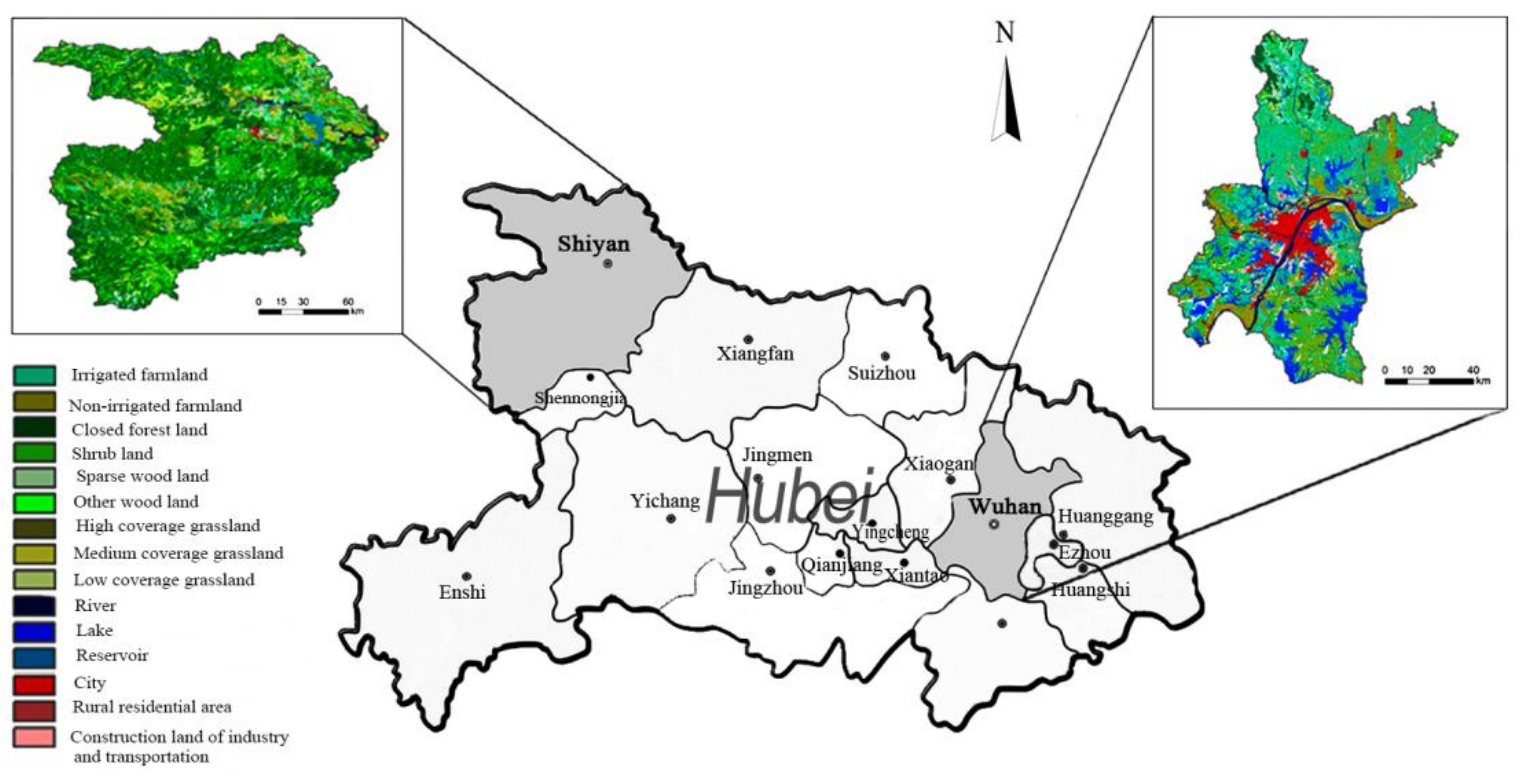

Figure 2. Study areas (Color should be used). 


\subsection{Questionnaire Design and Data Collection}

In general, the questionnaire collected information regarding (1) a brief description about the multifunction of agricultural land and agricultural land loss in the process of rapid urbanization in China (2) respondents' perception of the ecosystem services changes caused by rural-urban land conversion. Questions are designed according to the indices showed in Table 1 (i.e. "Do you think the Frequency of drought/floods/soil erosion/desertification increased?" If "yes," "Do you think it is related to rural-urban land conversion?" The five-point Likert scale (i.e. strongly disagree, mildly disagree, unsure, mildly agree and strongly agree) was used for respondents to choose (3) the socio-demographic information of area residents. It must be noted that, considering the specific indices of ecological well-being for the rural residents and urban residents are slightly different (Table 1), two different questionnaires were developed for these two groups of respondents. Specifically, rural residents were asked to compare the state of each kind of agroecosystem services before and after they lost their agricultural land (either positive or negative). If they think there were changes, they needed to indicate their opinion about whether those changes were related to rural-urban land conversion as well as the degree of relevance. Urban residents were asked to clarify their perception of the changes of each kind of agroecosystem services in the last fifteen years and also needed to indicate their views on whether those changes were related to rural-urban land conversion as well as the degree of relevance. To avoid investigators deviation in survey, we made no effort to force respondents to provide arguments; they were given the option to not provide an argument if they did not recognize any change $[3,70]$.

In this research, respondents are composed of two groups, rural residents and urban residents, defined according to the census registration system in China. "Rural residents" refers to people who are registered in a village and are generally eligible to be assigned agricultural land to work and make a living from. "Urban residents" are those who are registered as urban permanent residents and live in urban areas. Major Function Oriented Zoning Division (MFOZD) of China which is the guideline for optimizing the spatial pattern of regional development in China is put forward in 2011. Based on comprehensive analysis on regional resources and environment capacity, existing development density and potential, MFOZD divides the land space of China into a series of regional units according to a specified major function for each area. Some regions are planned as urbanizing regions (develop functional regions) whose major function is providing industrial products and services. Such areas are named "Priority Development Zone" or "Key Development Zone". Other regions are planned as agricultural regions (ecology functional areas) whose major function is providing ecological services. Such areas are named "Restricted Development Zone" or "Forbidden Development Zone". In order to investigate the impact of location on resident ecological well-being changes, Wuhan City and Shiyan City of Hubei Province are selected as study areas in this study. The two cities belong to a Key Development Zone and a Restricted Development Zone, respectively, according to the MFOZD of China.

Specifically, survey sites for rural residents were selected in the suburbs, where rural-urban land conversion has been frequent in recent years, while for urban residents the sites selected were open spaces or parks with a large flow of people. Ultimately, rural residents were surveyed in five administrative villages including Xingfu Village, Xiangyang Village, Fangliang Village, Liuhe Village and Chunhe Village in the Jiangxia District of Wuhan City, as well as in five administrative villages including Erdaopo Village, Caijialing Village, Wolonggang Village, Qinglongshan Village and Changping Village in Yunyang District of Shiyan City. Urban residents were surveyed in two central districts including the Hongshan District and Hangjiang District in Wuhan City as well as the Zhangwan District in Shiyan City. Sample size was estimated using the following sampling formula proposed by Scheaffer [71].

$$
N^{*}=N /\left[(N-1) \sigma^{2}\right]+1
$$


where $N^{*}$ is the needed theoretical sample size, $N$ is the population of study area, $\sigma$ is the sampling error $(\sigma=5 \%)$ [71]. By the end of 2015, the population of Wuhan and Shiyan were $1166.24 \times 10^{4}$ obtained from Wuhan Statistical Yearbook (2016) and Wuhan Statistical Yearbook (2016), including $729.57 \times 10^{4}$ urban residents and $436.67 \times 10^{4}$ rural residents. Accordingly, the sample size required for our research should be at least 402 . Considering the possible unresponsive or invalid samples, a total of 500 interviewees including 220 rural residents and 280 urban residents were randomly selected to be surveyed in the study areas mentioned above. Our research team which was composed of 8 postgraduates majoring in land resource management took face-to-face interviews to obtain data throughout the entire data collection periods in May 2015 and May 2016. Interviewers were asked to learn the contents of the questionnaire, especially the key issues and questions, through pre-training and pre-research to avoid investigators deviation. Besides, each interview was limited to 20-25 min to avoid length of residence time bias. After a brief description of the purpose of our research and obtaining permissions, we explained meaning of each index embedded in the questions of the questionnaire. And their answers were faithfully recorded by the interviewers. Ultimately, valid questionnaires were obtained from 209 rural residents and 266 urban residents after discarding invalid samples that included illogical or incomplete information.

\subsection{Methods}

\subsubsection{Fuzzy Synthetic Evaluation Model}

The core essence of Fuzzy Mathematics is regarding fuzzy concepts as study objects, employing fuzzy sets to determine imprecise or complex things and adopting the value of membership function to describe the degree to which a certain constituent belongs to a fuzzy set, which is employed to describe imprecision or vagueness [49]. The 'human ecological well-being' which is studied in this paper is one aspect of the concept of 'human well-being.' Researching the impacts of changes in life status and the subjective feelings and psychological characteristics of rural residents and urban residents as they are related to the ecosystem of agricultural land is essential to exploring this issue. Since most of these constituents are subjective and vague, the Fuzzy Synthetic Evaluation Model has a significant advantage for dealing with the subjective evaluation indexes is appropriate for this study.

$X$ is defined as the fuzzy set of resident state of ecological well-being. $W$ is a subset of $X$ which represents the possible change in ecological well-being as a result of rural-urban land conversion. Then, the ecological well-being function $W^{(n)}$ of the $n$th rural dweller or urban dweller can be expressed as follows:

$$
W^{(n)}=\left\{x, \mu_{w}(x)\right\}
$$

where $\mu_{w}(x)$ is the membership value function for $x$ belonging to $\mathrm{W}, \mu_{w}(x) \in[0,1]$ and $x \in \mathrm{X}$. It is well accepted that the higher the membership value is, the higher the ecological well-being level is. When the membership value is 1 , the ecological well-being of residents is the best; when it is 0 it is the worst and 0.5 is the medium state, neither good nor bad.

\subsubsection{Forms of Membership Function}

The membership function is one of the critical points of the fuzzy synthetic evaluation method and the membership function is different according to the different types of variables used. Variables are usually divided into three types: virtual dichotomous variables, virtual continuous variables and virtual qualitative variables. Let $x_{i j}$ represent the value of the $j$ th evaluation index of the $i$ th constituent of the resident's ecological well-being. $x_{i}$ is the $i$ th constituent subset of resident ecological well-being which is determined by the primary index $x_{i j}$. The initial index of ecological well-being is $x=\left[x_{11}, \cdots, x_{i j}, \cdots\right]$.

There are only two cases of virtual dichotomous variables which are commonly described by "true" or "false". For example, the question "Whether you and your family have had diseases that are 
related to ecosystem?" applies to the virtual dichotomous variable whose membership function can be expressed as follows:

$$
\mu\left(x_{i j}\right)=\left\{\begin{array}{cc}
0 & X_{i j}=0 \\
1 & X_{i j}=1
\end{array}\right.
$$

When the respondent has diseases due to ecological environmental pollution, $X_{i j}$ is 0 , otherwise $X_{i j}$ is 1 .

Virtual continuous variables are the indices that have continuous values. Their membership function can be expressed as follows. Equation (2) describes the positive relationship between $X_{i j}$ and the state of ecological well-being, while Equation (3) describes the negative relationship between them.

$$
\begin{gathered}
\mu\left(x_{i j}\right)=\left\{\begin{array}{cc}
0 & 0 \leq x_{i j} \leq x_{i j}^{\text {min }} \\
\frac{x_{i j}-x_{i j}^{\text {min }}}{x_{i j}^{\text {max }}-x_{i j}^{\text {min }}}, & x_{i j}^{\text {min }} \leq x_{i j} \leq x_{i j}^{\text {max }} \\
1 & x_{i j} \geq x_{i j}^{\max }
\end{array}\right. \\
\mu\left(x_{i j}\right)=\left\{\begin{array}{cc}
0 & 0 \leq x_{i j} \leq x_{i j}^{\text {min }} \\
\frac{x_{i j}^{\text {max }}-x_{i j}}{x_{i j}^{\text {max }}-x_{i j}^{\text {min }}}, & x_{i j}^{\min } \leq x_{i j} \leq x_{i j}^{\max } \\
1 & x_{i j} \geq x_{i j}^{\max }
\end{array}\right.
\end{gathered}
$$

where $x_{i j}^{\min }$ and $x_{i j}^{\max }$ represent the minimum and maximum value of $X_{i j}$ respectively.

Quantitative data are generally not available for some ecological well-being indices as some can be described by qualitative words only. Examples like this including the respondents' answers about "How satisfied are you with the air quality," "How about your nostalgia about rural life?" etc. These kinds of indexes are dealt with by a Likert scale which assigns the range of agroecosystem services from 1 through 5 at equidistant intervals. When satisfaction is measured, a larger value indicates a better ecological well-being state. On the contrary, when a negative indicator such as the frequency of agroecosystem-related meteorological disasters is measured, a larger value indicates a worse state. The membership function $\mu\left(x_{i j}\right)$ of the virtual qualitative variable is as follows:

$$
\begin{gathered}
\mu\left(x_{i j}\right)=\left\{\begin{array}{cc}
0 & 0 \leq x_{i j} \leq x_{i j}^{\text {min }} \\
\frac{x_{i j}-x_{i j}^{\text {min }}}{x_{i j}^{\max }-x_{i j}^{\text {min }}} & x_{i j}^{\text {min }} \leq x_{i j} \leq x_{i j}^{\max } \\
1 & x_{i j} \geq x_{i j}^{\max }
\end{array}\right. \\
\mu\left(x_{i j}\right)=\left\{\begin{array}{cc}
0 & 0 \leq x_{i j} \leq x_{i j}^{\min } \\
\frac{x_{i j}^{\text {max }}-x_{i j}}{x_{i j}^{\max }-x_{i j}^{\text {min }}}, & x_{i j}^{\min } \leq x_{i j} \leq x_{i j}^{\max } \\
1 & x_{i j} \geq x_{i j}^{\max }
\end{array}\right.
\end{gathered}
$$

where $x_{i j}^{m i n}$ and $x_{i j}^{m a x}$ represent the minimum and maximum value of $X_{i j}$ respectively.

\subsubsection{Weight Determination}

The Delphi method and the Analytic Hierarchy Process are commonly used in the calculation of weights but these are questioned due to the subjectivity of their results. This paper uses the weight definition proposed by [72] and employs the weight function as modified by [49,73].

$$
\omega_{i j}=\ln \left[1 / \overline{\mu\left(x_{i j}\right)}\right]
$$




\subsubsection{Aggregate the Membership Values of Indices}

According to the different types of the constituents described above in Section 3.3.2, corresponding membership functions are selected to calculate the indices membership value. And then the constituents' membership value is calculated according to the weight function. Therefore, the membership value of resident ecological well-being is as follows:

$$
W^{(n)}=\sum_{i=1}^{I} \mu\left(x_{i j}\right)^{n} \cdot \omega_{i j}^{(n)^{\prime}} / \sum_{i=1}^{I} \omega_{i}
$$

\subsubsection{Transformation Factors}

Well-being can be described as an individual's satisfaction with some aspects of his/her life as determined by his/her individual life states, physiological conditions and psychological factors [74]. It is recognized as the freedom and capability to choose different kinds of lifestyles in order to get access to a beautiful life, a healthy state, rich experiences, good social relations, cultural identity, a deep sense of belonging, respect and self-realization etc. in the process of natural ecosystem utilization and development $[75,76]$. Capability approach was put forward by Sen and he discussed the relationship between an individual's functioning, capability and values (or utilities which are defined in the usual terms of pleasures, happiness, or desire fulfillment) [77-79]. On this basis, the changes of farmers' economic and non-economic well-being in the process of rural-urban land conversion have been researched [49,51,73]. It figured out that the conversion degree and efficiency by which the goods or service changing to well-being are significantly different for each individual due to the differences in personal, social and environmental conditions which are conceptualized as "transformation factors". For example, different age groups have different anticipations when facing same environmental changes, more highly educated groups have better ability for livelihood selection and further environmental cognition [51,80]. In addition, an individual's preference for ecosystem services is affected by local environmental resources endowments to some extent [29]. Transformation factors could explain that why different people in same state have different levels of well-being. Sen (1999) studied five categories of conversion factors including the heterogeneity of individual, the diversity of the environment, the difference of social atmosphere, the difference of interpersonal relationship and the distribution of the family. Considering that the social atmosphere is stable in certain period of time in China, interpersonal relationship mainly reflect different social differences and ecological well-being is closely related to personal perception not the family internal distribution, this paper uses 'transformation factors' which influence the impact of rural-urban land conversion on an individual's ecological well-being to further investigate the effects of rural-urban land conversion. Socio-demographic characteristics including gender $\left(T_{1}\right)$, age $\left(T_{2}\right)$ and education level $\left(T_{3}\right)$, as well as zoning characteristic which is represented by location $\left(\mathrm{T}_{4}\right)$ are selected as transformation factors which are employed to analyze the differences of ecological well-being change between rural residents and urban residents.

\section{Results}

\subsection{Changes in Resident Ecological Well-Being}

According to the actual situation obtained through the survey, the membership values of rural resident ecological well-being indices including satisfaction with air quality, satisfaction with water quality, rural life nostalgia and children's rural experiences are all set as 0.5 which means that the state of rural resident ecological well-being mentioned above is neither good nor bad before rural-urban land conversion and the membership values of their ecological pollution-related diseases is set as 1 which means they did not get diseases due to ecological environment pollution. The membership values of urban residents' each ecological well-being index and overall ecological well-being are all 
set as 0.5 which means that the state of their ecological well-being is neither good nor bad before rural-urban land conversion. Resident ecological well-being changes are displayed in Table 2.

Table 2. Fuzzy evaluation results of resident ecological well-being change due to urban-rural land conversion.

\begin{tabular}{ccccccccc}
\hline \multirow{2}{*}{\begin{tabular}{c} 
Ecological Well-Being $\begin{array}{c}\text { Rural Residents } \\
\text { Constituents }\end{array}$ \\
\cline { 2 - 9 }
\end{tabular}} & \multicolumn{3}{c}{ Membership Value } & \multicolumn{2}{c}{ Weight } & Membership Value & Weight \\
\cline { 2 - 9 } & Before & After & Before & After & Before & After & Before & After \\
\hline$X_{1}$ & 0.553 & 0.509 & 0.593 & 0.676 & 0.500 & 0.437 & 0.657 & 0.828 \\
$X_{11}$ & 0.542 & 0.518 & 0.565 & 0.487 & - & - & - & - \\
$X_{12}$ & 0.564 & 0.500 & 0.573 & 0.693 & 0.500 & 0.437 & 0.657 & 0.828 \\
$X_{2}$ & 0.677 & 0.417 & 0.390 & 0.876 & - & - & - & - \\
$X_{21}$ & 0.770 & 0.397 & 0.261 & 0.924 & - & - & - & - \\
$X_{22}$ & 0.692 & 0.417 & 0.368 & 0.875 & - & - & - & - \\
$X_{23}$ & 0.615 & 0.438 & 0.486 & 0.826 & - & - & - & - \\
$X_{3}$ & 0.500 & 0.456 & 0.693 & 0.786 & 0.500 & 0.377 & 0.739 & 0.976 \\
$X_{31}$ & 0.500 & 0.420 & 0.693 & 0.868 & 0.500 & 0.373 & 0.739 & 0.986 \\
$X_{32}$ & 0.500 & 0.479 & 0.693 & 0.736 & 0.500 & 0.389 & 0.747 & 0.944 \\
$X_{33}$ & 0.500 & 0.380 & 0.693 & 0.968 & 0.500 & 0.437 & 0.715 & 0.828 \\
$X_{34}$ & 1.000 & 0.708 & 0.000 & 0.345 & 0.500 & 0.325 & 0.627 & 0.724 \\
$X_{4}$ & 0.500 & 0.250 & 0.693 & 1.385 & 0.500 & 0.520 & 0.723 & 0.654 \\
$X_{41}$ & 0.500 & 0.211 & 0.693 & 1.556 & - & - & - & - \\
$X_{42}$ & 0.500 & 0.301 & 0.693 & 1.201 & - & - & - & - \\
$X_{43}$ & - & - & - & - & 0.500 & 0.585 & 0.615 & 0.536 \\
$X_{44}$ & - & - & - & - & 0.500 & 0.473 & 0.763 & 0.749 \\
$X_{5}$ & 0.413 & 0.202 & 0.884 & 1.599 & 0.500 & 0.487 & 0.597 & 0.719 \\
$X_{51}$ & 0.413 & 0.202 & 0.884 & 1.599 & 0.500 & 0.487 & 0.597 & 0.719 \\
Overall & 0.507 & 0.326 & & & 0.500 & 0.447 & & \\
\hline
\end{tabular}

\subsubsection{Changes in the Ecological Well-Being of Rural Residents}

Rural resident overall level of ecological well-being in Wuhan City and Shiyan City declines from 0.507 to 0.326 with urban-rural land conversion, a decrease of $35.67 \%$ (Table 2; Figure 3). In fact, levels of all the five well-being constituents decline.

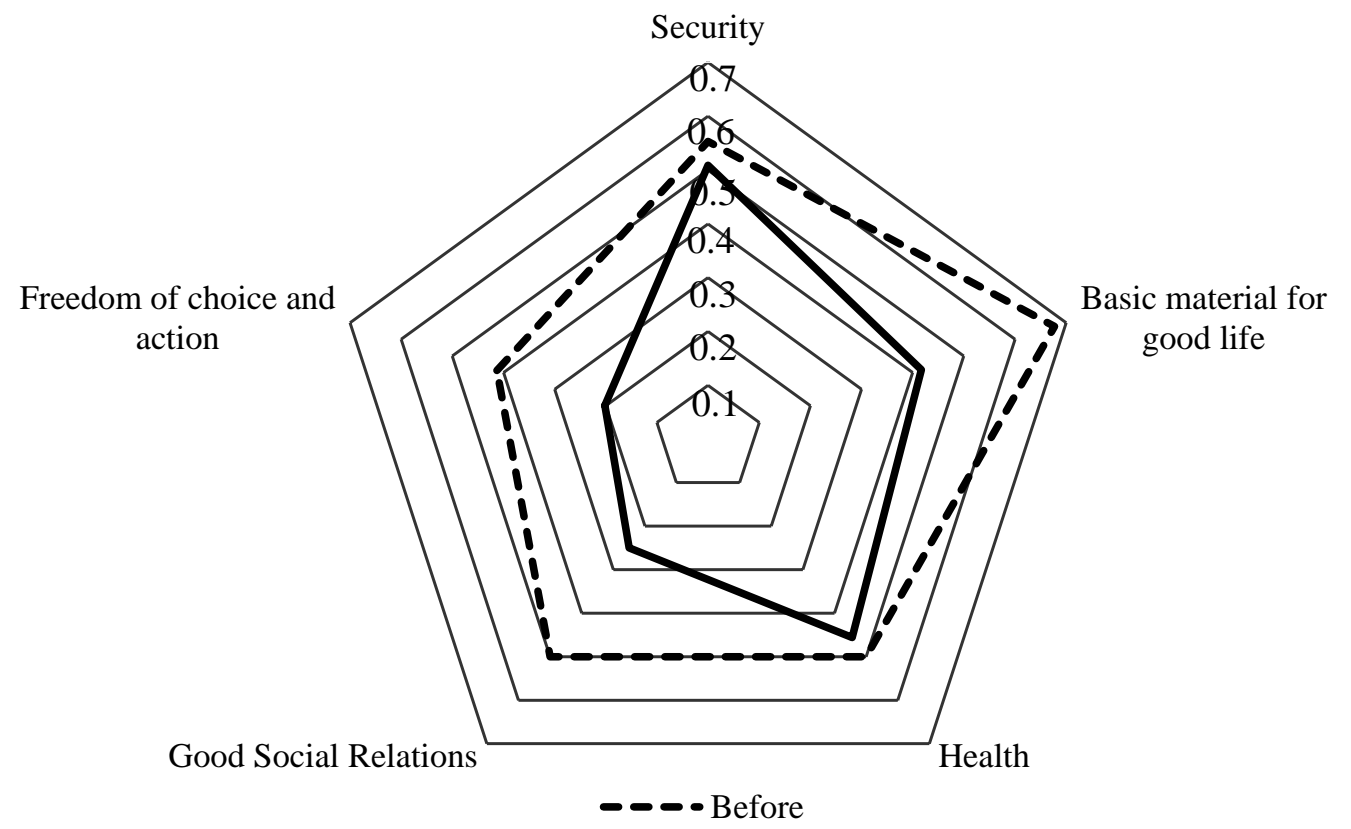

Figure 3. Membership value changes with the constituents of rural resident ecological well-being due to rural-urban land conversion. 


\section{- Security}

Before rural-urban land conversion, waste in rural areas was normally disposed of using traditional methods (landfill, incineration, natural piling, etc.). Most livestock manure, litter, food waste and other production and household waste can be degraded by agroecosystem automatically. The survey found that although garbage collection boxes were provided in the study area after rural-urban land conversion, the inadequate infrastructure of garbage disposal and untimely recycling of garbage made the environment worse and some of the wastes that are still disposed of using traditional methods cannot actually be degraded by the environment any more. Consequently, the level of rural resident ecological well-being due to recycling capacities declines (from 0.542 to 0.518 ). In addition, rural-urban land conversion promotes the transfer of a huge amount of agricultural land to urban construction land in China. Changes in the surface environment trigger off declines in soil water holding capacity, which further weakens the local environment's capacity for moderating floods, droughts and other extreme weather. Results show that the level of rural resident ecological well-being about the frequency of agroecosystem-related meteorological disasters declines by more than $10 \%$ (from 0.564 to 0.500 ). In general, the overall level of the rural resident ecological well-being as related to security declines by $7.96 \%$ (from 0.553 to 0.509 ).

\section{- Basic materials for a good life}

With the rural-urban land conversion, the ability to have a secure and adequate livelihood of rural resident turns from a good status (0.677) in a negative direction (0.417), which breaks through the fuzzy state of neither good nor bad (0.500) and changes toward a bad direction (Table 2). The way that rural residents get access to daily necessities is changed directly by rural-urban land conversion. Before rural-urban land conversion, rural residents basically obtain daily staple food (rice, flour and beans), vegetables and meats from their own farms. A small amount of supplementary vegetables and meat products are purchased from the market. When farmers lose their agricultural land after rural-urban land conversion, they are forced to buy daily foods in the market. Our survey reveals that this change greatly increases their living expenses and makes their lives difficult.

\section{- Health}

Due to rural-urban land conversion, agricultural land's original ecosystem services such as atmospheric regulation and air purification are weakened. In addition, air pollution, construction dust and sewage disposal soar early in land development. The two effects are superimposed so that the indices of air quality satisfaction and water quality satisfaction fall by $16.00 \%$ (from 0.500 to 0.420 ) and $4.20 \%$ (from 0.500 to 0.479 ) separately. Further, rural residents have to purchase for the original materials of food from the market which was previously acquired from farming. This raises the risk of food safety issues. The index of safety satisfaction with staples, vegetables and meat falls by $24.00 \%$ (from 0.500 to 0.380 ). Moreover, the membership value for the index of ecological pollution-related diseases rises $(0.708>0.500)$ after rural-urban land conversion but still has a certain degree of decline (from 1.000 to 0.708 ). On the whole, rural resident ecological well-being for the constituent of health is declines by $8.86 \%$ (from 0.500 to 0.456 ).

- Good social relations

This constituent is greatly influenced by rural-urban land conversion. Agricultural land is the material carrier of farming culture. Rural residents in China have a strong sense of dependence on agricultural land which is the basis of maintaining good social relations. Rural-urban land conversion cuts off their access to agroecosystem and cultures, which makes the indices of rural life nostalgia and children's rural experiences fall by $57.8 \%$ (from 0.500 to 0.211 ) and $39.8 \%$ (from 0.500 to 0.301 ) separately. As a whole, the membership value of the constituent of good social relations declines by $50.00 \%$ (from 0.500 to 0.250 ). 
- Freedom of choice and action

Rural residents' freedom of choice and action is constrained by their lower ability to make a living, so it is at a low level before the rural-urban land conversion $(0.413<0.500)$. With the loss of agricultural land, this constituent appears to be the constituent that declines most significantly, by $51.09 \%$ (from 0.413 to 0.202 ). The reason is that rural-urban land conversion directly reduces the natural capital of rural residents, which has a critical impact on their livelihoods [81]. In the surveyed area, the young landless rural residents have to work in township enterprises nearby or work in cities but their inadequate vocational skills make them poor. While older residents basically lose their way to make a living by farming and most of them can only stay at home. Considering the irreversibility of rural-urban land conversion, the decline of their freedom of choice and action is permanent.

\subsubsection{Changes in the Ecological Well-Being of Urban Residents}

Similar to the analysis of changes in rural resident ecological well-being, changes in the ecological well-being of urban residents can be summarized as follows briefly. Table 2 and Figure 4 show that the rural-urban land conversion makes the overall ecological well-being level drop from 0.500 to $0.447,10.64 \%$. Specifically, the three constituents of urban resident ecosystem well-being including security, health and freedom of choice and action all declines after the rural-urban land conversion. The constituent of health declines most significantly by $24.67 \%$ (from 0.500 to 0.377 ), within which the two indices including satisfaction with water quality and experience of ecological pollution-related diseases drop strikingly. The constituent of security declines by $12.60 \%$ (from 0.500 to 0.437 ) which reveals that urban residents approve of agricultural land's ecosystem services functions to a certain degree. Different from the rural residents, urban residents' freedom of choice and action is not affected by rural-urban land conversion significantly, it only drops by $2.60 \%$ (from 0.500 to 0.487 ) because urban residents are not closely linked with agricultural land and they have pluralistic livelihoods. It should be noted that the membership value of the constituent of good social relations rose slightly (from 0.500 to 0.520 ). Although the frequency of ecotourism reflects good social relations and has positive impact on resident ecological well-being, we discovered in the survey that the rise in this index's membership value is mainly due to improvement in people's living standards, allowing them to participate in ecological recreational activities more frequently. In other words, it is not closely related to the increase or decrease of agricultural land. 


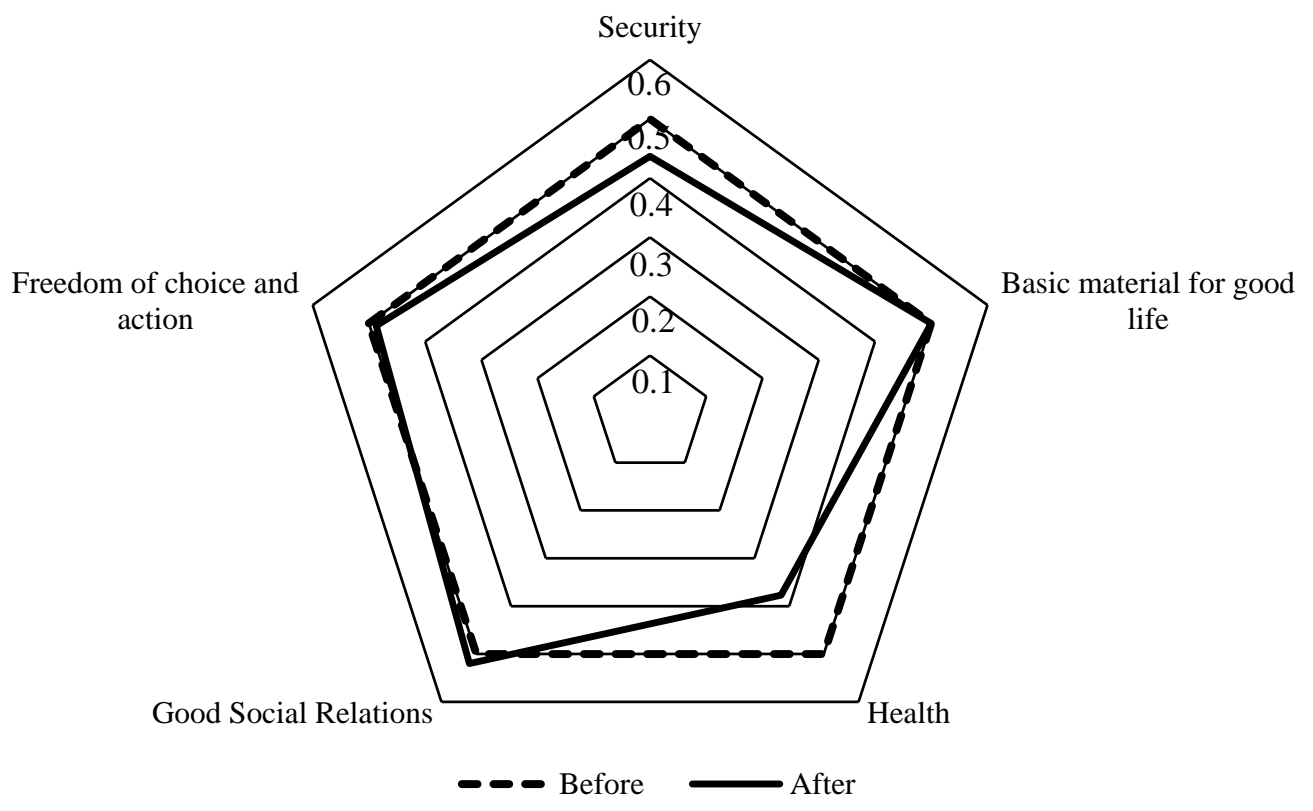

Figure 4. Membership value changes with the constituents of urban resident ecological well-being due to rural-urban land conversion.

\subsubsection{Comparison}

Comparing the ecological well-being of rural and urban residents, it can be observed that there are obvious differences between these two major stakeholder groups. The changes in rural residents overall ecological well-being and in each constituent of ecological well-being, are all greater than in urban residents. As direct users of agricultural land, rural residents are more closely and complexly interact with the agroecosystem than urban residents [82]. Owing to their high dependence on the agroecosystem, rural residents' ecological well-being unavoidably suffers from rural-urban land conversion. Rural residents are forced to move away from their original residence, lose their agricultural land and directly experience ecological deterioration, etc. Different than for rural residents, the link between urban residents and the agroecosystem is indirect, regardless of the spatial distance to the agricultural land or the intensity of interactions with the ecosystem.

\subsection{Impact of Transformation Factors on the Changes in Resident Ecological Well-Being}

\subsubsection{Rural Residents}

Table 3 displays the impact of transformation factors on the changes in rural resident ecological well-being.

- Impact of socio-demographic characteristics

Results show that the ecological well-being of the oldest sample group is the most affected, declining by $37.54 \%$, followed by the least educated sample group, declining by $37.11 \%$. Observing the impact of transformation factors on each constituent of rural resident ecological well-being, it is obvious that their age and education level have a momentous impact on both the ecological well-being constituents of good social relations and freedom of choice and action. The survey which reveals that the older and the less educated the interviewees are, the greater the dependence on their original way of life and the more difficult it is for them to find jobs after rural-urban land conversion. In other words, older and less educated rural residents have less opportunity to express cultural and spiritual values associated with the ecosystem and have less livelihood choices after losing their agricultural land. 
- Impact of zoning characteristics

As described above, there are fundamental differences between Wuhan City and Shiyan City in terms of zoning. Specifically, the former is mountainous, while the latter is plains; in view of the MFOZD of China, the former is in a Key Development Zone, while the latter is located in China's Restricted Development Zone; from the ecological perspective, the latter's ecological vulnerability is higher than the former's. The overall change in the rural resident ecological well-being in Shiyan City (declines by $38.19 \%$ ) is much greater than in Wuhan City (declines by $31.27 \%$ ) (Table 3). Zoning characteristics have greatest impact on the ecological well-being constituents of freedom of choice and action (declines from 0.426 to 0.211 for Wuhan City and from 0.413 to 0.198 for Shiyan City, both of which declines more than $50 \%$ ). The decline in the overall ecological well-being levels of rural residents in Wuhan City is mainly due to the decline in two constituents including basic material for a good life and freedom of choice and action. However, in Shiyan City, the dominant constituent in addition to the two above is the constituent of good social relations.

\subsubsection{Urban Residents}

Table 4 displays the impact of transformation factors on the changes in urban resident ecological well-being.

- Impact of socio-demographic characteristics

There are no significant differences in the impacts of socio-demographic characteristics on the overall levels of ecological well-being for urban residents. This field survey found urban residents' perceptions of changes in the ecological environment is more diverse and that they also have more diverse capabilities for adapting to the changes in the ecological environment brought about by rural-urban land conversion. In comparison, women's ecological well-being declines more than men's when rural-urban land conversion occurs and in the meantime, the older and the less educated the interviewees are, the greater their overall ecological well-being declines.

- Impact of zoning characteristics

Compared with Wuhan City with a higher level of urbanization and higher frequency of rural-urban land conversion, Shiyan City with its rich ecological resources endowment is part of China's key ecological function area and has higher environmental sensitivity. In other words, in comparison with Wuhan City, rural-urban land conversion occurring in Shiyan City will make the marginal benefit of ecosystem services decrease much more, resulting in the fact that urban residents in Shiyan City have more intense perceptions about ecological environment changes. 
Table 3. Fuzzy evaluation of rural resident ecological well-being changes using transformation factors.

\begin{tabular}{|c|c|c|c|c|c|c|c|c|c|c|c|c|c|c|c|}
\hline & \multirow{2}{*}{\multicolumn{2}{|c|}{ Transformation Factors }} & \multicolumn{2}{|c|}{$\overline{X_{1}}$} & \multicolumn{2}{|c|}{$\mathrm{X}_{2}$} & \multicolumn{2}{|c|}{$x_{3}$} & \multicolumn{2}{|c|}{$X_{4}$} & \multicolumn{2}{|c|}{$X_{5}$} & \multicolumn{3}{|c|}{ Overall } \\
\hline & & & Before & After & Before & After & Before & After & Before & After & Before & After & Before & After & Change (\%) \\
\hline \multirow{8}{*}{$\begin{array}{l}\text { Socio-demographic } \\
\text { characteristics }\end{array}$} & \multirow{2}{*}{$\mathrm{T}_{1}$} & Male & 0.556 & 0.511 & 0.678 & 0.415 & 0.500 & 0.459 & 0.500 & 0.255 & 0.416 & 0.208 & 0.509 & 0.331 & -35.04 \\
\hline & & Female & 0.552 & 0.508 & 0.675 & 0.421 & 0.500 & 0.452 & 0.500 & 0.248 & 0.409 & 0.196 & 0.506 & 0.323 & -36.08 \\
\hline & \multirow{4}{*}{$\mathrm{T}_{2}$} & $31-40$ & 0.565 & 0.508 & 0.702 & 0.421 & 0.500 & 0.461 & 0.500 & 0.286 & 0.422 & 0.223 & 0.513 & 0.347 & -32.40 \\
\hline & & $41-50$ & 0.557 & 0.517 & 0.674 & 0.409 & 0.500 & 0.452 & 0.500 & 0.249 & 0.414 & 0.205 & 0.508 & 0.326 & -35.78 \\
\hline & & $51-65$ & 0.548 & 0.499 & 0.659 & 0.420 & 0.500 & 0.449 & 0.500 & 0.231 & 0.405 & 0.198 & 0.503 & 0.318 & -36.85 \\
\hline & & $\geq 66$ & 0.550 & 0.506 & 0.679 & 0.416 & 0.500 & 0.459 & 0.500 & 0.233 & 0.403 & 0.187 & 0.503 & 0.314 & -37.54 \\
\hline & \multirow{2}{*}{$\mathrm{T}_{3}$} & Elementary school graduate and below & 0.561 & 0.507 & 0.693 & 0.422 & 0.500 & 0.451 & 0.500 & 0.246 & 0.408 & 0.188 & 0.507 & 0.319 & -37.11 \\
\hline & & High school graduate and above & 0.554 & 0.508 & 0.681 & 0.417 & 0.500 & 0.462 & 0.500 & 0.261 & 0.421 & 0.211 & 0.510 & 0.334 & -34.55 \\
\hline \multirow{2}{*}{$\begin{array}{c}\text { Zoning } \\
\text { characteristics }\end{array}$} & \multirow{2}{*}{$\mathrm{T}_{4}$} & Wuhan & 0.548 & 0.503 & 0.667 & 0.439 & 0.500 & 0.445 & 0.500 & 0.329 & 0.426 & 0.211 & 0.510 & 0.351 & -31.27 \\
\hline & & Shiyan & 0.557 & 0.514 & 0.691 & 0.412 & 0.500 & 0.469 & 0.500 & 0.217 & 0.413 & 0.198 & 0.508 & 0.314 & -38.19 \\
\hline
\end{tabular}

Table 4. Fuzzy evaluation result of urban resident ecological well-being changes using transformation factors.

\begin{tabular}{|c|c|c|c|c|c|c|c|c|c|c|c|c|c|}
\hline & \multirow{2}{*}{\multicolumn{2}{|c|}{ Transformation Factors }} & \multicolumn{2}{|c|}{$X_{1}$} & \multicolumn{2}{|c|}{$X_{3}$} & \multicolumn{2}{|c|}{$X_{4}$} & \multicolumn{2}{|c|}{$X_{5}$} & \multicolumn{3}{|c|}{ Overall } \\
\hline & & & Before & After & Before & After & Before & After & Before & After & Before & After & Change (\%) \\
\hline \multirow{8}{*}{$\begin{array}{l}\text { Socio-demographic } \\
\text { characteristics }\end{array}$} & \multirow{2}{*}{$\mathrm{T}_{1}$} & Male & 0.500 & 0.456 & 0.500 & 0.379 & 0.500 & 0.523 & 0.500 & 0.491 & 0.500 & 0.454 & -9.21 \\
\hline & & Female & 0.500 & 0.435 & 0.500 & 0.374 & 0.500 & 0.532 & 0.500 & 0.483 & 0.500 & 0.446 & -10.72 \\
\hline & \multirow{4}{*}{$\mathrm{T}_{2}$} & $31-40$ & 0.500 & 0.451 & 0.500 & 0.389 & 0.500 & 0.505 & 0.500 & 0.499 & 0.500 & 0.455 & -9.00 \\
\hline & & $41-50$ & 0.500 & 0.442 & 0.500 & 0.375 & 0.500 & 0.534 & 0.500 & 0.486 & 0.500 & 0.450 & -10.09 \\
\hline & & $51-65$ & 0.500 & 0.434 & 0.500 & 0.369 & 0.500 & 0.528 & 0.500 & 0.481 & 0.500 & 0.443 & -11.35 \\
\hline & & $\geq 66$ & 0.500 & 0.429 & 0.500 & 0.367 & 0.500 & 0.531 & 0.500 & 0.482 & 0.500 & 0.442 & -11.64 \\
\hline & \multirow{2}{*}{$\mathrm{T}_{3}$} & Middle school graduate & 0.500 & 0.466 & 0.500 & 0.376 & 0.500 & 0.533 & 0.500 & 0.486 & 0.500 & 0.448 & -10.42 \\
\hline & & High school graduate and above & 0.500 & 0.429 & 0.500 & 0.383 & 0.500 & 0.512 & 0.500 & 0.500 & 0.500 & 0.450 & -10.05 \\
\hline \multirow{2}{*}{$\begin{array}{c}\text { Zoning } \\
\text { characteristics }\end{array}$} & \multirow[b]{2}{*}{$\mathrm{T}_{4}$} & Wuhan & 0.500 & 0.421 & 0.500 & 0.373 & 0.500 & 0.527 & 0.500 & 0.509 & 0.500 & 0.450 & -9.91 \\
\hline & & Shiyan & 0.500 & 0.443 & 0.500 & 0.384 & 0.500 & 0.522 & 0.500 & 0.489 & 0.500 & 0.452 & -9.63 \\
\hline
\end{tabular}




\section{Discussion}

This study investigated changes in the ecological well-being of rural and urban residents due to rural-urban land conversion, as well as the impact of transformation factors. It confirms what previous studies have indicated: Changes in rural resident overall ecological well-being and in each constituent of ecological well-being are all greater than those of urban resident $[29,49,51,80$, 83]. And transformation factors including age, education level as well as location have significant influence on both rural and urban resident ecological well-being but the degree of influence is different. Rural residents and urban residents have different perception of the ecological services provided by agricultural land because they have a different degree of linkage with agricultural land and different knowledge of agroecosystem functions $[60,84,85]$. Rural resident ecological well-being experiences greater decline compared to urban residents, because they have closer and more direct contact with agricultural land [82]. Therefore, it is of great practical significance to analyze the ecological well-being changes brought out by rural-urban land conversion from the perspective of different interest groups. In addition, this is the first time location has been used in this way, representing zoning characteristics as a transformation factor for analyzing the effects of rural-urban land conversion on the ecological well-being changes in residents living in different areas with different ecological resources endowments. It could provide a theoretical foundation for regulating rural-urban land conversion by zoning.

This paper reveals the change amplitudes in ecological well-being brought out by rural-urban land conversion using a fuzzy synthetic evaluation model. How to quantify the currency value of the loss of resident ecological well-being is still a big challenge for researchers. The key point is how to transfer natural science field variables employed to quantify ecosystem services change into social science field variables which can be employed to quantify the human ecological well-being and measure changes. An effective linkage in needed. Additionally, different preferences for ecosystem services among interest groups should be identified in decision making and policy formulation, such that the response of interest groups and the priorities for ecosystem services compensation should be set up and decided both based on the revealed preference difference.

Previous studies have fully explained the significant effect of rural-urban land conversion on water, soil, climate and other aspects of ecosystem $[38,55,69]$. Combining the assessment of ecosystems by MA with the findings in this paper, it is found that the ecosystem functions of agricultural land including supply services, regulatory services, cultural services and support services are degraded or limited due to agricultural land loss which is a result of rural-urban land conversion. Consequently, resident ecological well-being, consisting of security, basic material for a good life, health, good social relations and freedom of choice and action declines. In China, this loss of ecological well-being ca not be compensated due to the lack of an eco-compensation mechanism. In other words, the loss of ecological well-being brought about by rural-urban land conversion exists in the form of a negative externality which has not been accounted for as a part of the cost of rural-urban land conversion. It can be recognized as one of the explanations for why the loss agricultural land in China is excessive. Therefore, it is necessary to establish efficient eco-compensation policies for rural-urban land conversion from the perspective of ecological well-being.

\section{Conclusions and Future Work}

Rural-urban land conversion in the process of urbanization in China causes a sharp decrease in agricultural land, resulting in the loss of its original ecosystem services. Consequently, people's opportunities for accessing various ecological services from agro-ecosystems are reduced and their freedom of choice and actions is limited. The ecological consequences in the form of negative externalities lead to a decline in people's ecological well-being. This paper constructs ecological well-being indices for rural and urban residents and then estimates the changes in resident ecological well-being caused by rural-urban land conversion using the Fuzzy Synthetic Evaluation Model. In addition, the differences of ecological well-being changes and the impact of transformation factors for ecological well-being changes between rural and urban residents are analyzed. Compared to 
urban residents, rural resident ecological well-being declines more due to rural-urban land conversion, because of the more serious ecological damage. For rural residents, all the five ecological well-being constituents including security, basic material for a good life, health, good social relations and freedom of choice and action show varying degrees of deterioration and the constituent of freedom of choice and action deteriorates most seriously. For urban residents, after rural-urban land conversion, all the ecological well-being constituents except the constituent of good social relations shows varying degrees of deterioration and the constituent of health deteriorates most seriously. The impact of transformation factors are also investigated in this paper. Two socio-demographic characteristics including age and education level as well as zoning characteristics have influence on both rural and urban resident well-being. Moreover, we argue that there is a need for quantitative measurement of agroecosystem services and for the construction of an ecological compensation mechanism for the process of rural-urban land conversion in China, as it is essential for regulating rural-urban land conversion and maintaining ecological well-being.

Our research is a starting point for quantifying the changes in ecological well-being of residents caused by rural-urban land conversion and examining the impact of transformation factors in this process. Since it was conducted at a provincial level, further research in a larger study area in future research is needed.

Acknowledgments: The authors acknowledge the funding received from the projects "Regulation of rural-urban land conversion based on negative externalities governance (No. 71303260)" and "Differential Eco-Compensation Mechanism for Farmland Protection under the Spatial Control of Land Use: Scale Dependence and Spatial difference (No. 71774174)" of the National Natural Science Foundation of China (NSFC).

Author Contributions: Min Song and Manman Han conceived and designed this research; Manman Han performed the field survey; Min Song and Manman Han analyzed the data; Min Song and Lynn Huntsinger wrote the paper.

Conflicts of Interest: The authors declare no conflict of interest.

\section{References}

1. Smith, L.M.; Case, J.L.; Smith, H.M.; Harwell, L.C.; Summers, J.K. Relating ecoystem services to domains of human well-being: Foundation for a U.S. index. Ecol. Indic. 2013, 28, 79-90. [CrossRef]

2. Leisher, C.; Samberg, L.H.; Buekering, P.V.; Sanjayan, M. Focal Areas for Measuring the Human Well-Being Impacts of a Conservation Initiative. Sustainability 2013, 5, 997-1010. [CrossRef]

3. Quintas-Soriano, C.; Castro, A.J.; Castro, H.; García-Llorente, M. Impacts of land use change on ecosystem services and implications for human well-being in Spanish drylands. Land Use Policy 2016, 54, 534-548. [CrossRef]

4. Kazana, V.; Kazaklis, A. Exploring quality of life concerns in the context of sustainable rural development at the local level: A Greek case study. Reg. Environ. Chang. 2009, 9, 209-219. [CrossRef]

5. Summers, J.K.; Smith, L.M. The Role of Social and Intergenerational Equity in Making Changes in Human Well-Being Sustainable. Ambio 2014, 43, 718-728. [CrossRef] [PubMed]

6. Wang, B.; Tang, H.; Xu, Y. Perceptions of human well-being across diverse respondents and landscapes in a mountain-basin system, China. Appl. Geogr. 2017, 85, 176-183. [CrossRef]

7. Zhang, A.; Yang, G.; Lu, H. The influence of rural-urban land conversion on the sustainable development of agriculture. Theory Mon. 1999, 12, 7-11.

8. Liu, Y.; Tang, W.; He, J.; Liu, Y.; Ai, T.; Liu, D. A land-use spatial optimization model based on genetic optimization and game theory. Comput. Environ. Urban Syst. 2015, 49 (Suppl. C), 1-14. [CrossRef]

9. Stobbe, T. The Economics and Externalities of Agricultural Land in the Urban Fringe. Ph.D. Thesis, University of Victoria, Victoria, BC, Canada, 2008.

10. Eagle, A.J. Threats to Agriculture at the Extensive and Intensive Margins: Economic Analyses of Selected Land-Use Issues in the US West and British Columbia. Ph.D. Thesis, Wageningen University, Wageninge, The Netherlands, 2009.

11. Chen, Z.; Ju, D.; Zhang, A. Measuring external benefits of agricultural land preservation: An application of choice experiment in Wuhan, China. Acta Ecol. Sin. 2013, 33, 3213-3221. [CrossRef] 
12. Racevskis, L.; Ahearn, M.; Alberini, A.; Bergstrom, J.; Boyle, K.B.; Libby, L.; Paterson, R.; Welsch, M. Improved information in support of a national strategy for open land policies: A review of literature and report on research in progress. In Proceedings of the 24th International Conference of Agricultural Economists, Berlin, Germany, 13-18 August 2000; pp. 1-16.

13. Song, M.; Han, M. Compensation mechanism of rural-urban land conversion in the perspective of ecological well-being: Literature review and framework construction. Issues Agric. Econ. 2016, 11, 94-102.

14. Smith, H.F.; Sullivan, C.A. Ecosystem services within agricultural landscapes-Farmers' perceptions. Ecol. Econ. 2014, 98, 72-80. [CrossRef]

15. Dai, G.; Na, R.; Dong, X.; Yu, B. The dynamic change of herdsmen well-being and ecosystem services in grassland of Inner Mongolia: Take Xilinguole League as example. Acta Ecol. Sin. 2014, 34, 2422-2430.

16. Liu, J.; Kuang, W.; Zhang, Z.; Xu, X.; Qin, Y.; Ning, J.; Zhou, W.; Zhang, S.; Li, R.; Yan, C.; et al. Spatiotemporal characteristics, patterns, and causes of land-use changes in China since the late 1980s. J. Geogr. Sci. 2014, 24, 195-210. [CrossRef]

17. Yang, L.; Zhen, L.; Li, F.; Wei, Y.; Jiang, L.; Cao, X.; Long, X. Impacts of ecosystem services change on human well-being in the Loess Plateau. Resour. Sci. 2010, 32, 849-855.

18. Poor, P.J.; Brule, R. An Investigation of the Socio-Economic Aspects of Open Space and Agricultural Land Preservation. J. Sustain. Agric. 2007, 30, 165-176. [CrossRef]

19. Da Silva, J.M.C.; Prasad, S.; Diniz-Filho, J.A.F. The impact of deforestation, urbanization, public investments, and agriculture on human welfare in the Brazilian Amazonia. Land Use Policy 2017, 65, 135-142. [CrossRef]

20. Hamann, M. Exploring Connections in Social-Ecological Systems: The Links between Biodiversity, Ecosystem Services, and Human Well-Being in South Africa. Ph.D. Thesis, Stockholm Resilience Centre, Stockholm University, Stockholm, Sweden, 2016.

21. Fischer, A.; Eastwood, A. Coproduction of ecosystem services as human-nature interactions-An analytical framework. Land Use Policy 2016, 52, 41-50. [CrossRef]

22. Offiong, R.A.; Eteng, O.E. Effect of urbanization on greenareas in Calabar metropolis. Int. J. Eng. Sci. 2014, 3, 71-75.

23. Sallustio, L.; Quatrini, V.; Geneletti, D.; Corona, P.; Marchetti, M. Assessing land take by urban development and its impact on carbon storage: Findings from two case studies in Italy. Environ. Impact Assess. Rev. 2015, 54, 80-90. [CrossRef]

24. Song, M.; Lei, Y. Negative externalities from different directions of rural-urban land conversion using CE Method. China Popul. Resour. Environ. 2017, 27, 28-39.

25. Liang, M.; Yang, Z. Research on ecological well-being loss and compensation of non-agricultural land transference. J. Gansu Sci. 2014, 26, 35-38.

26. Reyers, B.; Biggs, R.; Cumming, G.S.; Elmqvist, T.; Hejnowicz, A.P.; Polasky, S. Getting the measure of ecosystem services: A social-ecological approach. Front. Ecol. Environ. 2013, 11, 268-273. [CrossRef]

27. Fischer, J.; Hartel, T.; Kuemmerle, T. Conservation policy in traditional farming landscapes. Conserv. Lett. 2012, 5, 167-175. [CrossRef]

28. Zhang, W.; Ricketts, T.H.; Kremen, C.; Carney, K.; Swinton, S.M. Ecosystem services and dis-services to agriculture. Ecol. Econ. 2007, 64, 253-260. [CrossRef]

29. Soy-Massoni, E.; Langemeyer, J.; Varga, D.; Sáez, M.; Pintó, J. The importance of ecosystem services in coastal agricultural landscapes: Case study from the Costa Brava, Catalonia. Ecosyst. Serv. 2016, 17, 43-52. [CrossRef]

30. Qu, F.; Lu, N.; Feng, S. Effects of land use change on carbon emissions. China Popul. Resour. Environ. 2011, 10, 76-83.

31. Lee, Y.C.; Ahern, J.; Yeh, C.T. Ecosystem services in peri-urban landscapes: The effects of agricultural landscape change on ecosystem services in Taiwan's western coastal plain. Landsca. Urban Plan. 2015, 139, 137-148. [CrossRef]

32. Kroeger, T.; Casey, F. An assessment of market-based approaches to providing ecosystem services on agricultural lands. Ecol. Econ. 2007, 64, 321-332. [CrossRef]

33. Plieninger, T.; Bieling, C. Resilience and the Cultural Landscape: Understanding and Managing Change in Human-Shaped Environments; Cambridge University Press: Cambridge, UK, 2012; pp. 1-366.

34. Li, S.; Zhang, A. Research of rural-urban land conversion and social loss based on the demonstration study of Wuhan city circle. Resour. Sci. 2014, 36, 303-310. 
35. Chen, Z.; Zhang, A.; Zhang, X.; Song, M. Measurement of external costs in rural-urban land conversion processes. Resour. Sci. 2010, 32, 1141-1147.

36. Long, H.; Liu, Y.; Hou, X.; Li, T.; Li, Y. Effects of land use transitions due to rapid urbanization on ecosystem services: Implications for urban planning in the new developing area of China. Habitat Int. 2014, 44 (Suppl. C), 536-544. [CrossRef]

37. Chuai, X.; Huang, X.; Wu, C.; Li, J.; Lu, Q.; Qi, X.; Zhang, M.; Zuo, T.; Lu, J. Land use and ecosystems services value changes and ecological land management in coastal Jiangsu, China. Habitat Int. 2016, 57, 164-174. [CrossRef]

38. Millennium Ecosystem Assessment. Ecosystems and Human Well-Being: Synthesis; Island Press: Washington, DC, USA, 2005.

39. Singh, R.; Singh, G. Ecosystem services: A bridging concept of ecology and economics. Ecol. Quest. $2017,25$. [CrossRef]

40. Sinare, H.; Gordon, L.J.; Enfors Kautsky, E. Assessment of ecosystem services and benefits in village landscapes-A case study from Burkina Faso. Ecosyst. Serv. 2016, 21, 141-152. [CrossRef]

41. Brander, L.; Brouwer, R.; Wagtendonk, A. Economic valuation of regulating services provided by wetlands in agricultural landscapes: A meta-analysis. Ecol. Eng. 2013, 56 (Suppl. C), 89-96. [CrossRef]

42. Omer, A.; Pascual, U.; Russell, N. A theoretical model of agrobiodiversity as a supporting service for sustainable agricultural intensification. Ecol. Econ. 2010, 69, 1926-1933. [CrossRef]

43. Landis, D.A. Designing Agricultural Landscapes for Biodiversity-Based Ecosystem Services. Basic Appl. Ecol. 2017, 18, 1-12. [CrossRef]

44. Barrena, J.; Nahuelhual, L.; Báez, A.; Schiappacasse, I.; Cerda, C. Valuing cultural ecosystem services: Agricultural heritage in Chiloé island, southern Chile. Ecosyst. Serv. 2014, 7 (Suppl. C), 66-75. [CrossRef]

45. Van Zanten, B.T.; Zasada, I.; Koetse, M.J.; Ungaro, F.; Häfner, K.; Verburg, P.H. A comparative approach to assess the contribution of landscape features to aesthetic and recreational values in agricultural landscapes. Ecosyst. Serv. 2016, 17, 87-98. [CrossRef]

46. Van Berkel, D.B.; Verburg, P.H. Spatial quantification and valuation of cultural ecosystem services in an agricultural landscape. Ecol. Indic. 2014, 37, 163-174. [CrossRef]

47. Li, H.; Huang, X.; Kwan, M.P.; Bao, H.X. H.; Jefferson, S. Changes in farmers' welfare from land requisition in the process of rapid urbanization. Land Use Policy 2015, 42, 635-641. [CrossRef]

48. Huang, Y. Study on Estimating the Value of Cultivated Land Ecosystem Services and Economic Compensation of Cultivated Land Protection in Zhuzhou Area. Master Thesis, Hunan Normal University, Changsha, China, 2015.

49. Gao, J.; Qiao, R.; Zhang, A. Fuzzy evaluation of farmers' well-being in rural-urban land conversion based on Sen's capability approach. Manag. World 2007, 6, 45-56.

50. Peng, K.; Zhang, P.; Zhang, A. Welfare balance of different interest groups during rural-urban land conversion. Chin. J. Popul. Resour. Environ. 2009, 7, 57-64.

51. Peng, K.; Zhu, H. The Impacts of Rural-Urban Land Conversion on the Welfare of Different Aged Land-lost Farmers. China Land Sci. 2015, 29, 71-78.

52. Wang, B.; Tang, H. Human well-being and its applications and prospects in Ecology. J. Ecol. Rural Environ. 2016, 32, 697-702.

53. Venkatachalam, L. The contingent valuation method: A review. Environ. Impact Assess. Rev. 2004, $24,89-124$. [CrossRef]

54. Freeman, A.M., III; Herriges, J.A.; Kling, C.L. The Measurement of Environmental and Resource Values: Theory and Methods, 3rd ed.; RFF Press: New York, NY, USA, 2014.

55. Yang, X.; Burton, M.; Zhang, A. Estimation of farmland eco-compensation criteria based on latent class model: A case of discrete choice experiment. China Popul. Resour. Environ. 2016, 7, 27-36.

56. Cai, Y.; Zhang, A. Researching progress and trends of agricultural land's ecological compensation under land use planning control. J. Nat. Resour. 2010, 25, 868-880.

57. Guo, Z. The Farmland Protection System of China: Implementation Performance Evaluation, Implementation Deviation and Optimization Methods. J. Zhengzhou Univ. 2017, 50, 64-68.

58. Liu, Y. Study on the Level of China Agricultural Ecological Welfare and Promotion Strategy: Case of Hubei Province. Ph.D. Thesis, Huazhong Agricultural University, Wuhan, China, 2014. 
59. Zhang, L. The breaking and reconstruction of nutrient recycling chains in agro-ecosystem in China. Ecol. Econ. 2006, 2, 103-105.

60. Peng, J.; Tian, L.; Liu, Y.; Zhao, M.; Hu, Y.; Wu, J. Ecosystem services response to urbanization in metropolitan areas: Thresholds identification. Sci. Total Environ. 2017, 607-608, 706-714. [CrossRef] [PubMed]

61. Francis, C.A.; Hansen, T.E.; Fox, A.A.; Hesje, P.J.; Nelson, H.E.; Lawseth, A.E.; English, A. Farmland conversion to non-agricultural uses in the US and Canada: Current impacts and concerns for the future. Int. J. Agric. Sustain. 2012, 10, 8-24. [CrossRef]

62. Chen, Z.; Zhang, A.; Song, M.; Zhang, Z. Measuring external costs of rural-urban land conversion: An empirical study in Wuhan, China. Acta Ecol. Sin. 2016, 36, 30-35. [CrossRef]

63. Glenk, K.; Colombo, S. Modelling outcome-related risk in choice experiments. Aust. J. Agric. Resour. Econ. 2013, 57, 559-578. [CrossRef]

64. Garcia, X. The value of rehabilitating urban rivers: The Yarqon River (Israel). J. Environ. Econ. Policy 2014, 3, 323-339. [CrossRef]

65. Baró, F.; Palomo, I.; Zulian, G.; Vizcaino, P.; Haase, D.; Gómez-Baggethun, E. Mapping ecosystem service capacity, flow and demand for landscape and urban planning: A case study in the Barcelona metropolitan region. Land Use Policy 2016, 57, 405-417. [CrossRef]

66. Hart, J.F. Urban Encroachment on Rural Areas. Geogr. Rev. 1976, 66, 1-17. [CrossRef]

67. Swinton, S.M.; Lupi, F.; Robertson, G.P.; Hamilton, S.K. Ecosystem services and agriculture: Cultivating agricultural ecosystems for diverse benefits. Ecol. Econ. 2007, 64, 245-252. [CrossRef]

68. $\mathrm{Yu}, \mathrm{K}$. Three proposals for preventing the potential damage by building the new countryside and protecting the local cultural landscape and the industrial heritage. Chin. Landsc. Archit. 2006, 8, 8-12.

69. Li, H.; Zhang, A. Ecological compensation boosted ecological protection and human well-being improvement. Acta Ecol. Sin. 2013, 33, 1065-1070.

70. Sherren, K.; Verstraten, C. What Can Photo-Elicitation Tell Us About How Maritime Farmers Perceive Wetlands as Climate Changes? Wetlands 2012, 33, 65-81. [CrossRef]

71. Scheaffer, R.L.; Mendenhall, W. Elementary Survey Sampling, 6th Revised ed.; Brooks Cole: Boston, MA, USA, 2005; p. 486.

72. Cheli, B.; Lemmi, A. A totally fuzzy and relative approach to the multidimensional analysis of poverty. Econ. Notes 1995, 24, 115-134.

73. Gao, J.; Qiao, R. Analysis on variation in farmers welfare after rural-urban land conversion. China Popul. Resour. Environ. 2011, 21, 99-105.

74. Schirmer, J.; Berry, H.L.; O'Brien, L.V. Healthier land, healthier farmers: Considering the potential of natural resource management as a place-focused farmer health intervention. Health Place 2013, 24, 97-109. [CrossRef] [PubMed]

75. Smith, C.L.; Clay, P.M. Measuring subjective and objective well-being: Analyses from five marine commercial fisheries. Human Organ. 2010, 69, 158-169. [CrossRef]

76. Qi, J.; Yang, Z. Global climate changes and human well-being and adaptability. Acad. Mon. 2014, 46, 21-26.

77. Sen, A.K. Commodities and Capabilities; North-Holland: Amsterdam, The Ntherlands, 1985; pp. 1-104.

78. Nussbaum, M.; Sen, A.K. Capability and Well-Being; Clarendon Press: Oxford, UK, 1993.

79. Sen, A. Development as Freedom; Oxford University Press: New York, NY, USA, 1999.

80. Erickson, J.J.; Martinengo, G.; Hill, E.J. Putting work and family experiences in context: Differences by family life stage. Human Relat. 2010, 63, 955-979. [CrossRef]

81. Ding, S.; Zhang, Y.; Ma, Z. Research on changes of livelihood capabilities of rural households encountered by land acquisition: Based on improvement of sustainable livelihood approach. Issues Agric. Econ. 2016, 6, 25-34.

82. Skandrani, Z.; Daniel, L.; Jacquelin, L.; Leboucher, G.; Bovet, D.; Prevot, A.C. On Public Influence on People's Interactions with Ordinary Biodiversity. PLoS ONE 2015, 10, e0130215. [CrossRef] [PubMed]

83. Peel, D.; Berry, H.L.; Schirmer, J. Farm exit intention and wellbeing: A study of Australian farmers. J. Rural Stud. 2016, 47, 41-51. [CrossRef] 
84. Pan, Y.; Marshall, S.; Maltby, L. Prioritising ecosystem services in Chinese rural and urban communities. Ecosyst. Serv. 2016, 21, 1-5. [CrossRef]

85. Jiang, C.; Jin, J.; Li, L. Non-market valuation of cultivated land protection using cvm: A case study of Wenling City. Resour. Sci. 2011, 33, 1955-1961.

(C) 2018 by the authors. Licensee MDPI, Basel, Switzerland. This article is an open access article distributed under the terms and conditions of the Creative Commons Attribution (CC BY) license (http:/ / creativecommons.org/licenses/by/4.0/). 